\title{
COMO TEMOS PESQUISADO A AIRBNB? \\ CARACTERÍSTICAS DAS PESQUISAS EM PERIÓDICOS CIENTÍFICOS DA ADMINISTRAÇÃO E DO TURISMO ENTRE 2008 E $2018^{1}$
}

\author{
Leonardo Bars Humes \\ Mestrando do Programa de Pós-Graduação em Ciências da Comunicação da Escola de Comunicações e \\ Artes da Universidade de São Paulo (PPGCOM - ECA/USP) \\ Bolsista CAPES \\ Bacharel em Comunicação Social - Publicidade e Propaganda \\ leonardobarshumes@gmail.com \\ Otávio Bandeira de Lamônica Freire \\ Doutor em Ciências da Comunicação pela Escola de Comunicações e Artes da Universidade de São Paulo \\ (ECA-USP) \\ otfreire@usp.br
}

\section{Resumo}

Objetivo do estudo: O objetivo desta pesquisa é apresentar as características dos artigos que analisam a Airbnb publicados nos principais periódicos científicos internacionais e nos periódicos científicos nacionais pertencentes ao campo do Turismo e ao campo da Administração entre 2008 e 2018.

Metodologia/abordagem: Este estudo fundamenta-se em um estudo bibliométrico, empregando uma revisão sistemática seguida de uma análise bibliométrica realizada por meio de um estudo de co-citações a partir de uma análise fatorial exploratória.

Originalidade/Relevância: Até o momento não foi identificada nenhuma revisão sistemática sobre a Airbnb que apresentasse as características das produções apontando as similaridades e diferenças entre a produção internacional publicada nos principais periódicos científicos e a produção científica nacional, nem uma análise bibliométrica que indicasse a constituição teórica que sustenta as investigações sobre Airbnb.

Principais resultados: Os artigos da amostra concentram-se em alguns periódicos, apresentando um crescimento exponencial ao longo dos anos, sendo majoritariamente não baseados em teoria, utilizando abordagem quantitativa, empregando como principais técnicas estatísticas regressões e SEM, focando em efeitos econômicos e empregando como principal unidade de análise dados secundários. O autor com mais publicações é Daniel Guttentag. As citações feitas pela amostra fundamentam-se em três fatores, nomeados (1) 'Pricing e Impacto Econômico', (2) 'Sustentáculo Teórico’ e (3) ‘Estado da Arte e Estudos Futuros'.

Contribuições teóricas/metodológicas: Este artigo agrega a literatura sobre o tema ao avançar os achados feitos por Humes e Freire (2018) e Dann, Teubner e Weinhardt (2019) por meio da realização de um estudo bibliométrico.

Palavras-chave: Airbnb. Revisão Sistemática. Estudo Bibliométrico. Turismo. Administração.

\section{Cite como}

American Psychological Association (APA)

Humes, L. B., \& Freire, O. B. de L. (2020). Como temos pesquisado a Airbnb? Características das pesquisas em periódicos científicos da administração e do turismo entre 2008 e 2018. PODIUM Sport, Leisure and Tourism Review, São Paulo, 9(1), 117-140. https://doi.org/10.5585/podium.v9i1.15820.

\footnotetext{
${ }^{1}$ O presente trabalho foi realizado com apoio da Coordenação de Aperfeiçoamento de Pessoal de Nível Superior - Brasil (CAPES) - Código de Financiamento 001.
} 


\title{
HOW HAVE WE SEARCHED AIRBNB? \\ CHARACTERISTICS OF RESEARCH IN ADMINISTRATION AND TOURISM SCIENTIFIC JOURNALS BETWEEN 2008 AND 2018
}

\begin{abstract}
Objective of the study: This research aims to present the characteristics of articles that analyze Airbnb published in the main international scientific journals and national scientific journals that belong to the field of tourism and the field of administration between 2008 and 2018.
\end{abstract}

Methodology / approach: This study is based on a bibliometric study, employing a systematic review followed by a bibliometric analysis performed through a co-citations study based on an exploratory factor analysis.

Originality / Relevance: To date, no systematic review of Airbnb has been identified that presents the characteristics of productions pointing to similarities and differences between the international production published in the main scientific journals and the national scientific production, nor a bibliometric analysis that indicates the theoretical constitution that supports the Airbnb investigations.

Main results: The articles in the sample are concentrated in specific journals, presenting an exponential growth over the years, being mostly not based on theory, using quantitative approach, using as main statistical techniques regressions and SEM, focusing on economic effects and employing as main unit of research secondary data. The author with the most publications is Daniel Guttentag. Quotations from the sample are based on three factors, namely (1) 'Pricing and Economic Impact', (2) 'Theoretical Support' and (3) 'State of the Art and Future Studies'.

Theoretical / Methodological Contributions: This article aggregates to the literature on the subject by advancing the findings made by Humes and Freire (2018) and Dann, Teubner and Weinhardt (2019) by conducting a bibliometric study.

Keywords: Airbnb. Systematic Review. Bibliometric Study. Tourism. Management.

\section{¿CÓMO HEMOS BUSCADO AIRBNB? \\ CARACTERÍSTICAS DE LA INVESTIGACIÓN EN REVISTAS CIENTÍFICAS DE ADMINISTRACIÓN Y TURISMO ENTRE 2008 Y 2018}

\section{Resumén}

Objetivo del estudio: El propósito de esta investigación es presentar las características de los artículos que analizan Airbnb publicados en las principales revistas científicas internacionales y científicas nacionales en el campo del Turismo y la Administración entre 2008 y 2018.

Metodología / enfoque: Este estudio se basa en un estudio bibliométrico, que emplea una revisión sistemática seguida de un análisis bibliométrico realizado a través de un estudio de co-citas a partir de un análisis factorial exploratorio. 
Originalidad / Relevancia: Hasta la fecha, no se ha identificado una revisión sistemática de Airbnb que presente las características de las producciones al señalar las similitudes y diferencias entre la producción internacional publicada en las principales revistas científicas y la producción científica nacional, ni un análisis bibliométrico que indique la constitución teórica que respalda las investigaciones sobre Airbnb.

Resultados principales: Los artículos de la muestra se concentran en algunas revistas, muestran un crecimiento exponencial a lo largo de los años, y no se basan principalmente en la teoría, utilizan un enfoque cuantitativo, utilizan como principales técnicas estadísticas regresiones y SEM, se centran en los efectos económicos y utilizan como unidad principal de análisis datos secundarios. El autor con más publicaciones es Daniel Guttentag. Las citas de la muestra se basan en tres factores, a saber: (1) "Precios e impacto económico", (2) "Apoyo teórico" y (3) "Estado del arte y estudios futuros".

Contribuciones teóricas / metodológicas: Este artículo agrega a la literatura sobre el tema al avanzar los hallazgos realizados por Humes y Freire (2018) y Dann, Teubner y Weinhardt (2019) mediante la realización de un estudio bibliométrico.

Palabras clave: Airbnb. Revisión sistemática. Estudio bibliométrico. Turismo. Administración.

\section{Introdução}

O século XXI tem sido palco de diversas mudanças que tem afetado padrões e hábitos até então estabelecidos. O surgimento de novas tecnologias - com especial destaque para as de compartilhamento ponto-a-ponto ${ }^{2}$ - tem permitido o desenvolvimento de 'novas' possibilidades que afetam diretamente o modo pelo qual realizamos ações cotidianas, impactando inclusive os modos de consumir, viajar e de se hospedar (Zimmermann, Humes, \& Meira, 2019). Esse movimento contribuiu para que antigas - porém agora resignificadas - formas de consumo, como o consumo colaborativo, voltassem à tona, conferindo potencial a um segmento até então pouco explorado e culminando na criação de espaços que propiciaram o surgimento de diversas empresas as quais tem suas atuações pautadas nos pilares do consumo colaborativo.

Por agregar múltiplas vantagens às partes envolvidas, este fenômeno tem conquistado grande espaço na vida da população, apresentando potencial para representar uma fatia considerável das economias nacionais no futuro (PWC, 2015) e ocupando um espaço até então pouco preenchido (Belk, 2010).

No Brasil, um estudo realizado entre maio e junho de 2019 pela Confederação Nacional de Dirigentes Lojistas (CNDL) e pelo Serviço de Proteção ao Crédito (SPC Brasil) com 837 consumidores de todas as capitais do país mostrou que $74 \%$ das pessoas que participaram do estudo já utilizaram ao menos uma vez algum serviço associado ao consumo colaborativo (SPC, 2019). Além disso, 81\% dos respondentes afirmaram estar dispostos a engajarem-se em práticas de consumo colaborativo em até 2 anos - um aumento de $13 \%$ em relação à pesquisa anterior. A porcentagem relativa a disposição de engajar-se é semelhante independentemente da faixa etária e classe social do respondente (SPC, 2019).

\footnotetext{
${ }^{2} \mathrm{O}$ conceito de ponto-a-ponto consiste em um processo no qual os sujeitos envolvidos em uma tarefa são conectados diretamente um(ns) ao(s) outro(s), sem a presença de mediação humana explícita para a ocorrência dessa conexão.
}

PODIUM Sport, Leisure and Tourism Review | São Paulo | v. 9 | n. 1 | p. 117-140 | jan./abr. 2020 
Nos Estados Unidos, haviam 44,8 milhões de adultos utilizando serviços de consumo colaborativo em 2016, com a expectativa de que esse número cresça para 86,5 milhões em 2021 (Lock, 2019). Um estudo conduzido em 2017 com 1220 residentes do Reino Unido apontou que $23 \%$ da população utiliza alguma plataforma de consumo colaborativo, um aumento de 60\% em relação aos 18 meses anteriores (Warwick, 2018). Além disso, o consumo colaborativo pode representar uma parcela significante da renda daqueles que oferecem serviços por meio de suas plataformas (Davidson, 2016). Nesse sentido, fica claro que o consumo colaborativo é um fenômeno global consolidado, alterando significativamente dinâmicas previamente estabelecidas.

Seus atores impactam diversos segmentos, incluindo o de hospitalidade, de modo que se anteriormente grandes conglomerados do ramo hoteleiro disputavam entre si fatias do mercado de hospedagem, atualmente estes mesmos grupos precisam lidar com a concorrência de movimentos e organizações que nasceram nos meios digitais e possuem em suas raízes aspectos colaborativos como o CouchSurfing e a Airbnb, que agora participam ativamente e de forma efetiva no segmento de acomodações em nível global. Isso fica claro quando observa-se, por exemplo, que no Brasil $38 \%$ dos respondentes que já consumiram algum serviço de consumo colaborativo utilizaram o aluguel de curto prazo de moradias (SPC, 2009), enquanto que no Reino Unido esta modalidade de consumo colaborativo é a mais utilizada (Warwick, 2018).

Esse processo de emersão do consumo colaborativo é uma tendência que ocorre em função e a partir da expansão tecnológica e dos meios de comunicação, que ao modelarem uma sociedade em rede permitem a circulação de novas ideias e sentidos, além de facilitarem o acesso a bens e serviços por meio de aplicativos que barateiam os custos, tornando-os mais acessíveis a população e fomentando sua adesão ao criarem novos segmentos atrelados a práticas consolidadas, atendendo assim múltiplos perfis e necessidades (Bezerra \& Ferreira, 2018).

No segmento do Turismo e, mais especificamente, no cenário de hospedagem, a expansão tecnológica e do consumo colaborativo contribuíram para a criação de plataformas que auxiliaram a ressignificação do conceito de hospedagem, originando o chamado 'turismo 2.0' (William \& Martel, 2008), no qual cria-se um ecossistema turístico apoiado pelas redes sociais digitais e alimentado por aqueles que nele participam, criando dinâmicas complexas (Moreira \& Gomes, 2018). Nesse enfoque, os novos espaços permitiram uma maior interação entre as partes envolvidas, criando um ambiente no qual a hospedagem é complementada pela experiência do processo relacional, ou seja, por tudo que acontece desde a busca pelo espaço até o término de sua utilização (Molz, 2014).

Além disso, a proposta de utilizar espaços antes impensáveis - como casas - para hospedagens baseadas no aluguel de curto prazo amplia e corrobora o apelo 'diferenciado' associado ao movimento colaborativo, que busca a ressignificação e a alteração de práticas de consumo (Botsman \& Rogers, 2011). Paralelamente, os apelos únicos de uma casa podem evocar a ritualização do lar (McCracken, 2012). As configurações distintas - e muitas vezes únicas - dos espaços disponíveis nas plataformas de consumo colaborativo contribuem para a transformação de casas em espaços repletos de significados ausentes nos espaços dos quartos de hotéis, padronizados na intenção de representarem materialmente a imagem das marcas as quais encontram-se vinculados.

Essa característica particular dessas plataformas contribui para a co-criação simbólica da identidade e dos significados atrelados às marcas (Yannopoulo, Moufahim, \& Bian, 2013), reforçando as conexões com os sujeitos e incentivando seu consumo ao promover laços de identificação, contribuindo para a extensão do self por meio do consumo (Belk, 2013). 
A principal empresa prestadora dessa categoria de serviço colaborativo e exemplo desse cenário é a Airbnb, a qual será o objeto da análise apresentada neste trabalho.

A opção por estudar a Airbnb se baseia em dois pontos relevantes: primeiramente, existem indícios que apontam para o fato de que a Airbnb apresenta impactos reais nas receitas dos hotéis (Zervas, Proserpio, \& Byers, 2017). Essa questão, além de confirmar a reconfiguração do segmento de hospedagem, realça a importância das investigações sobre a Airbnb tanto para o campo acadêmico do Turismo quanto para praticantes desse mercado.

$\mathrm{O}$ segundo ponto reside no fato de que embora existam diversos estudos sobre esta plataforma, contribuindo para o entendimento sobre aspectos importantes como os motivos associados à adesão ao serviço (Guttentag, Smith, Potwarka, \& Havitz, 2018), a avaliação do boca-a-boca eletrônico na plataforma (Bridges \& Vásquez, 2016), práticas de precificação (Wang \& Nicolau, 2017) e co-criação e co-destruição de valor (Camilleri \& Neuhofer, 2017), por exemplo, até o presente momento não foi detectada nenhuma revisão sistemática sobre a Airbnb que apresentasse as características das produções sobre esta temática apontando as similaridades e diferenças entre a produção internacional publicada nos principais periódicos científicos e a produção científica nacional, nem uma análise bibliométrica que indicasse a constituição teórica que sustenta as investigações sobre Airbnb. Dessa forma, a realização deste estudo contribui para a literatura ao mapear o desenvolvimento dos estudos sobre Airbnb e ao oferecer avenidas de pesquisa a partir dos achados das investigações previamente realizadas.

Dessa forma, o presente trabalho busca responder a seguinte questão de pesquisa: Quais são as características dos artigos que analisam a Airbnb publicados nos principais periódicos científicos internacionais e nos periódicos científicos nacionais pertencentes ao campo do Turismo e ao campo da Administração entre 2008 e 2018 ?

A escolha por analisar periódicos pertencentes a estes dois campos específicos se baseia nos fatos de que a natureza da Airbnb enseja a investigação das publicações realizadas no campo do Turismo, que por sua vez encontra-se aninhado na área de Administração. Dessa forma, espera-se que publicações abordando este objeto estejam também localizadas nos periódicos vinculados à Administração. Portanto, este estudo concentra seus esforços em descobrir quais são os padrões que os artigos componentes da amostra apresentam.

$\mathrm{O}$ artigo encontra-se dividido em quatro partes: inicialmente, apresenta-se a Airbnb. Posteriormente, detalha-se a metodologia. A sessão subsequente apresenta os resultados encontrados e uma análise destes à luz da questão de pesquisa proposta e do cenário em que o fenômeno 'Airbnb' se encontra. Por fim, apresentam-se considerações finais, limitações do estudo e sugestões para estudos futuros.

\section{Novas formas de hospedagem: a Airbnb}

A Airbnb foi fundada em 2008, mas a ideia surgiu um ano antes através de três amigos que utilizaram um site simples para anunciar o apartamento que dividiam como disponível para aluguel, visando encontrar algum delegado que fosse a uma conferência política que estava ocorrendo na cidade de São Francisco na época e estivesse interessado em uma hospedagem mais barata que a dos hotéis da cidade. Para isso, divulgaram o apartamento como "AirBed \& Breakfast" (Guttentag, 2015).

Após uma remodelação feita no site, o serviço hoje consiste em uma plataforma online na qual qualquer pessoa pode ofertar um cômodo livre em sua casa para aluguel - mesmo que seja apenas uma sala - ou então alugar um espaço oferecido (Edelman \& Luca, 2014). Em seu surgimento, a plataforma apresentou algumas características que eram únicas para aquele momento, como valer-se da Internet para criar uma plataforma que podia oferecer a seus

PODIUM Sport, Leisure and Tourism Review | São Paulo | v. 9 | n. 1 | p. 117-140 | jan./abr. 2020 
consumidores a possibilidade de experiências mais autênticas e preços virtuosamente mais baratos do que os de quartos de hotéis, o que a fez ser classificada como disruptiva (Guttentag, 2015).

O serviço conta atualmente com mais de seis milhões de espaços disponíveis em mais de 191 países (Airbnb, 2019), possuindo, por exemplo, mais quartos que toda a rede de hotéis Marriott, que é a maior rede hoteleira do mundo (Marriot, 2015), tendo uma penetração global de grande capilaridade e contando com aproximadamente trinta marcas e aproximadamente 1,2 milhão de acomodações disponíveis em mais de 110 países diferentes, o que representa um hotel em cada quinze do planeta (Ap, 2016).

Esse fato contribui para realçar a relevância da Airbnb no segmento de acomodações, especialmente quando considerado que suas características a levaram a superar a até então maior rede de acomodações do mundo, que, face a inovação trazida pela plataforma, lançou um serviço para competir com a Airbnb no segmento de aluguel de residências (Touryalai, 2019). Além disso, possui valor de mercado na casa dos trinta bilhões de dólares, sendo a quarta startup mais valiosa do mundo e valendo mais que a rede Hilton, a qual vale aproximadamente vinte e três bilhões de dólares (Borneli, 2016).

\section{Metodologia}

Visando entender o que tem sido pesquisado sobre a Airbnb, este estudo é de cunho exploratório pautado em um estudo bibliométrico. Emprega como primeira técnica de análise uma revisão sistemática que, para Sampaio e Mancini (2007, p. 84), trata-se de uma técnica que "assim como outros tipos de estudo de revisão, é uma forma de pesquisa que utiliza como fonte de dados a literatura sobre determinado tema", apresentando uma síntese dos estudos associados a um objeto específico "mediante a aplicação de métodos explícitos e sistematizados de busca, apreciação crítica e síntese da informação selecionada".

O desenvolvimento de uma revisão sistemática implica na construção de uma fundação concreta para o desenvolvimento de teorias, delimitação de áreas com múltiplas pesquisas e o descobrimento de áreas em que faz-se necessário o desenvolvimento de novos estudos (Webster \& Watson, 2002).

Este estudo teve sua estrutura definida a partir de uma adaptação da pesquisa realizada por Manoharan e Singal (2017), englobando a realização de quatro etapas: (1) definição do intervalo de tempo que o estudo analisará, (2) seleção das fontes de dados, (3) seleção dos artigos e (4) análise dos artigos.

Dada a complexidade do objeto analisado, observar o que é publicado em periódicos científicos de diferentes categorias é altamente recomendável. Dessa forma, a presente investigação propõe-se a analisar as publicações realizadas sobre a Airbnb entre 2008 e 2018, tendo como corpus inicial de pesquisa os 40 principais periódicos científicos internacionais pertencentes aos campos do Turismo e da Administração escolhidos a partir do indicador $H$-Index ${ }^{3}$, bem como todos os periódicos científicos nacionais dessas áreas indexados no repositório de periódicos $\mathrm{Spell}^{4}$.

\footnotetext{
${ }^{3}$ A lista com todos os periódicos avaliados pelo H-Index e a definição de como ele é calculado está acessível para consulta pública e de forma gratuita na plataforma online Scimago Journal \& Country Rank, disponível em: https://www.scimagojr.com/.

${ }^{4}$ O Spell é um repositório nacional que reúne periódicos científicos das áreas da Administração, Contabilidade, Economia, Engenharia e Turismo. Disponível em: http://www.spell.org.br/.
} 
Para realização deste estudo, os pesquisadores acessaram o website das bases de dados Scopus e Spell e realizaram uma busca para identificar artigos que contivessem o termo 'Airbnb' no título, resumo ou nas palavras-chave e que foram publicados entre 2008 e 2018.

No caso da busca realizada no Scopus, ainda, foi adicionado um filtro para que apenas papers publicados nos 40 principais periódicos internacionais de Turismo e Administração previamente selecionados fossem exibidos.

Posteriormente, os artigos encontrados foram analisados através de uma tabela híbrida proveniente da união das tabelas utilizadas por Kim, Hayes, Avant e Reid (2014) e Santos e Freire (2013) em suas pesquisas. Os elementos que compõem essa tabela são: autoria do artigo, ano de publicação do trabalho, periódico em que se encontra localizado, escopo do periódico, resumo do artigo, palavras-chave, presença/ausência de teoria, nome das teorias utilizadas, variável dependente (se houver), variável independente (se houver), orientação de pesquisa (empírica/não empírica), abordagem de pesquisa (qualitativa/quantitativa/método misto), método de pesquisa, mídia de interesse, tipo de efeito, unidade de análise, resultados, implicações e indicações para estudos futuros (sim/não). Para fins de comparação de características, os achados da revisão sistemática foram analisados a partir do local de publicação (internacional versus nacional).

A segunda fase desta investigação consiste na realização de uma análise bibliométrica por meio de um estudo de co-citações a partir de uma análise fatorial exploratória (AFE). Um estudo bibliométrico é uma técnica estatística que permite analisar características específicas de uma amostra a partir de diversas abordagens quantitativas, auxiliando o entendimento de novas temáticas (Quevedo-Silva, Santos, Brandão, \& Vils, 2016). A operacionalização da análise bibliométrica seguiu as indicações de Quevedo-Silva et al. (2016). Para esse estudo, foram incluídos na matriz de co-citação apenas artigos que possuíam três ou mais citações.

A AFE é uma técnica estatística de agrupamento que possibilita observar como um determinado conjunto de variáveis se articula, visualizar padrões que permitam a criação de questionários para mensuração de variáveis latentes e reduzir um conjunto de dados com a manutenção da essência das informações que o compõe (Field, 2009). Assim, sua aplicação nessa pesquisa torna-se útil ao possibilitar a observação da constituição dos territórios teóricos que sustentam as investigações sobre Airbnb. A condução da AFE foi realizada a partir das recomendações de Hair, Black, Babin, Anderson e Tatham (2009).

\section{Análise e discussão dos resultados}

Essa seção apresenta e discute os achados da revisão sistemática e do estudo bibliométrico realizado a partir de uma análise de co-citação realizada por meio de uma análise fatorial exploratória à luz da questão de pesquisa proposta e do cenário em que o fenômeno 'Airbnb' se encontra.

\subsection{Revisão Sistemática}

Após a realização do procedimento de busca, os autores depararam-se com um total de 52 artigos publicados em periódicos internacionais do campo do Turismo, 01 publicado em periódicos internacionais do campo da Administração e 04 publicados em periódicos nacionais, totalizando uma amostra final de 57 artigos distribuídos entre 14 periódicos. O quadro 1 apresenta a distribuição de artigos entre os periódicos.

PODIUM Sport, Leisure and Tourism Review | São Paulo | v. 9 | n. 1 | p. 117-140 | jan./abr. 2020 
Os dados apresentados, para além de mostrarem uma maior concentração de artigos nos periódicos International Journal of Hospitality Management e International Journal of Contemporary Hospitality Management, salientam alguns aspectos interessantes. Uma característica compartilhada por essas revistas é a de que ambas valorizam a interdisciplinaridade e a multidisciplinaridade. Nesse sentido, ensejam uma produção plural sobre o objeto de estudo, contribuindo tanto para tornar os periódicos mais atrativos para publicações sobre a plataforma quanto para aumentar o alcance dos artigos ali publicados, criando um circuito retroalimentado. Além disso, a natureza dessas revistas, voltadas a hospitalidade, dialogam com a natureza intrínseca da Airbnb, promovendo uma maior afinidade das pesquisas sobre a plataforma com essas publicações.

Quadro 1 - Distribuição dos artigos por periódicos científicos

\begin{tabular}{|l|c|c|}
\hline \multicolumn{2}{|c|}{ Distribuição dos artigos por periódico científico } \\
\hline Periódicos Internacionais & Quantidade de Artigos & H-Index \\
\hline $\begin{array}{l}\text { International Journal of } \\
\text { Hospitality Management }\end{array}$ & 13 & 93 \\
\hline $\begin{array}{l}\text { International Journal of } \\
\text { Contemporary Hospitality } \\
\text { Management }\end{array}$ & 13 & 67 \\
\hline Tourism Management & 07 & 159 \\
\hline $\begin{array}{l}\text { Journal of Travel \& Tourism } \\
\text { Marketing }\end{array}$ & 05 & 58 \\
\hline Current Issues in Tourism & 04 & 57 \\
\hline Tourism Economics & 03 & 50 \\
\hline Tourism Geographies & 03 & 49 \\
\hline Journal of Travel Research & 02 & 114 \\
\hline Annals of Tourism Research & 01 & 83 \\
\hline Journal of Sustainable Tourism & 01 & 88 \\
\hline Organization & 01 & \\
\hline & & \\
\hline Periódicos Nacionais & & - \\
\hline & 02 & - \\
\hline Marketing \& Tourism Review & 01 & - \\
\hline $\begin{array}{l}\text { Perspectivas em Gestão \& } \\
\text { Conhecimento }\end{array}$ & 01 & \\
\hline Revista Eletrônica de Estratégia \& \\
Negócios
\end{tabular}

Fonte: Elaborado pelos autores.

A produção nacional, por sua vez, encontra-se distribuída em três periódicos, com a revista Marketing \& Tourism Review concentrando mais publicações. Aqui, majoritariamente, a Airbnb é posicionada como o objeto de pesquisa, sendo a discussão teórico-conceitual marcada pelas múltiplas esferas que constituem o fenômeno da economia do compartilhamento/colaborativa.

A análise de aspectos que fundamentam as relações entre hóspedes e hospedeiros (Matos \& Marques, 2018) e a percepção que anfitriões da Airbnb têm sobre o consumo colaborativo (Alves, Brandão, \& Valdevino, 2018), por exemplo, ilustram que a Airbnb constitui-se como um valioso caso que permite entender as mudanças pelas quais o turismo e a hospitalidade vem passando em nível mundial. Contribui, também, para entender e discutir o 
papel dos novos atores e a reconfiguração das funções exercidas pelas partes tradicionais nesse processo em um segmento até então marcado por alterações pouco disruptivas.

Em relação a distribuição de publicações ao longo dos anos, a figura 1 demonstra que os artigos internacionais estudando a Airbnb têm crescido de forma exponencial nos últimos anos. O destaque fica para o ano de 2018, que concentrou mais da metade da produção no período analisado. Os artigos nacionais acompanham essa tendência, com 03 produções em 2018 e 01 em 2017.

Figura 1 - Quantidade de artigos por ano

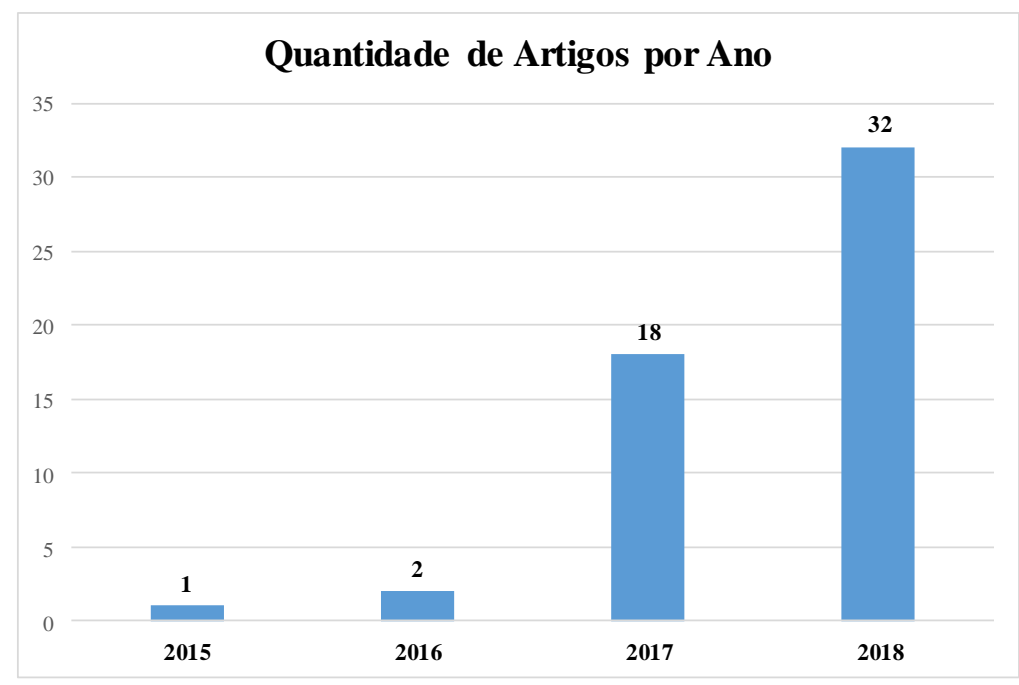

Fonte: Elaborado pelos autores.

Isso pode ter ocorrido em função do trabalho de Guttentag (2015), considerado seminal na temática, que mapeou diversos caminhos profícuos de pesquisa sobre a Airbnb, estimulando o desenvolvimento de estudos abordando este objeto. Pode ser considerado, portanto, o marco inicial das investigações sobre o objeto. Além disso, tal descoberta mostra que a Airbnb tem chamado a atenção da comunidade acadêmica. As alterações que ela tem causado no cenário da hospedagem reafirmam a importância de analisá-la a partir das diversas dimensões das quais ela pode ser estudada, buscando assim compreender o máximo possível sobre mecanismos por ela mobilizados e seus impactos nas múltiplas esferas sociais.

Conforme retratado na figura 2, percebe-se que na produção internacional analisada ainda predominam estudos não baseados em teoria frente aos baseados em teoria. A produção nacional segue o mesmo caminho, com todos os estudos sendo não baseados em teoria.

Esse achado torna-se compreensível quando considerado que por tratar-se de uma seara de pesquisa relativamente recente, ainda existe um vasto campo de conhecimento a ser descoberto e estruturado. Desta forma, a utilização de abordagens exploratórias - não baseadas em teoria - permitem aprofundar os conhecimentos em um novo tópico de interesse para posteriormente permitir a formulação de hipóteses mais robustas e fundamentadas, além do desenvolvimento de novas teorias que auxiliem o entendimento acerca das relações existentes em um ambiente/fenômeno desconhecido ou pouco estudado, criando familiaridade com o universo a ser investigado (Piovesan \& Temporini, 1995). 
Figura 2 - Quantidade de artigos por ano

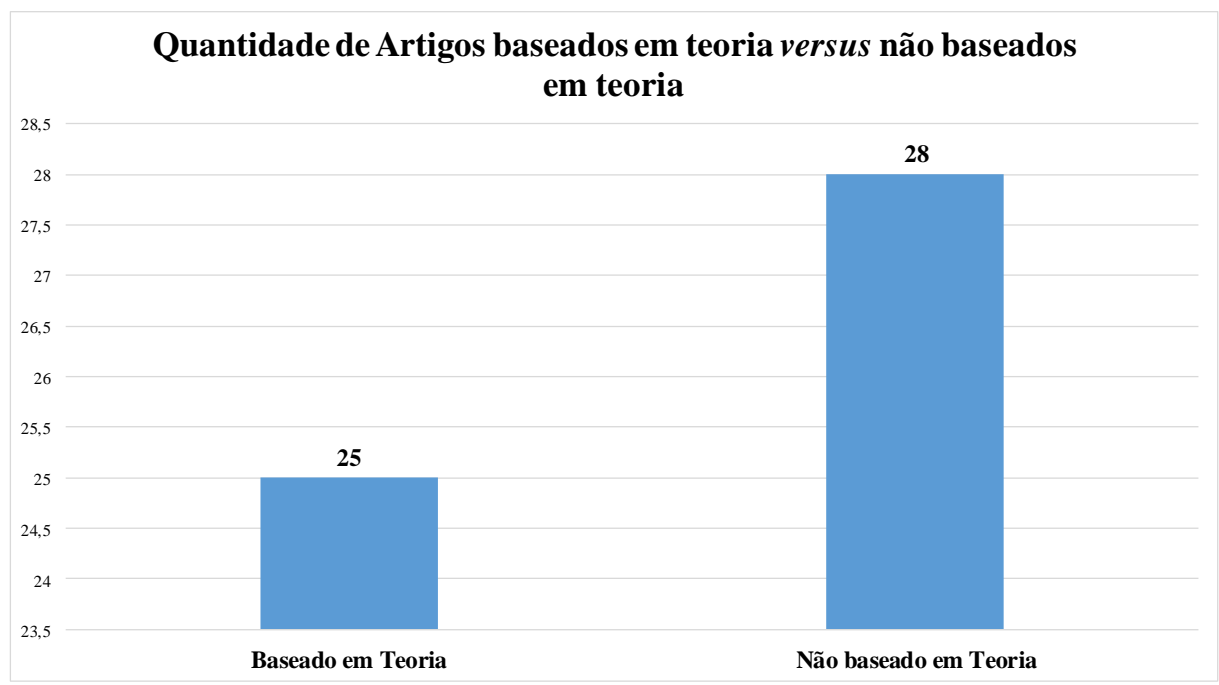

Fonte: Elaborado pelos autores.

Por sua vez, os estudos baseados em teoria (figura 3) apresentam o emprego de um amplo leque de teorias, com o predomínio do emprego da 'teoria do comportamento planejado', com três ocorrências, seguida pela 'teoria da inovação disruptiva', 'teoria da difusão de inovações', 'teoria da sinalização', 'teoria da troca social', 'teoria do prospecto' e da 'teoria dos preços hedônicos', todas com duas ocorrências.

Figura 3 - Teorias mais utilizadas nos artigos

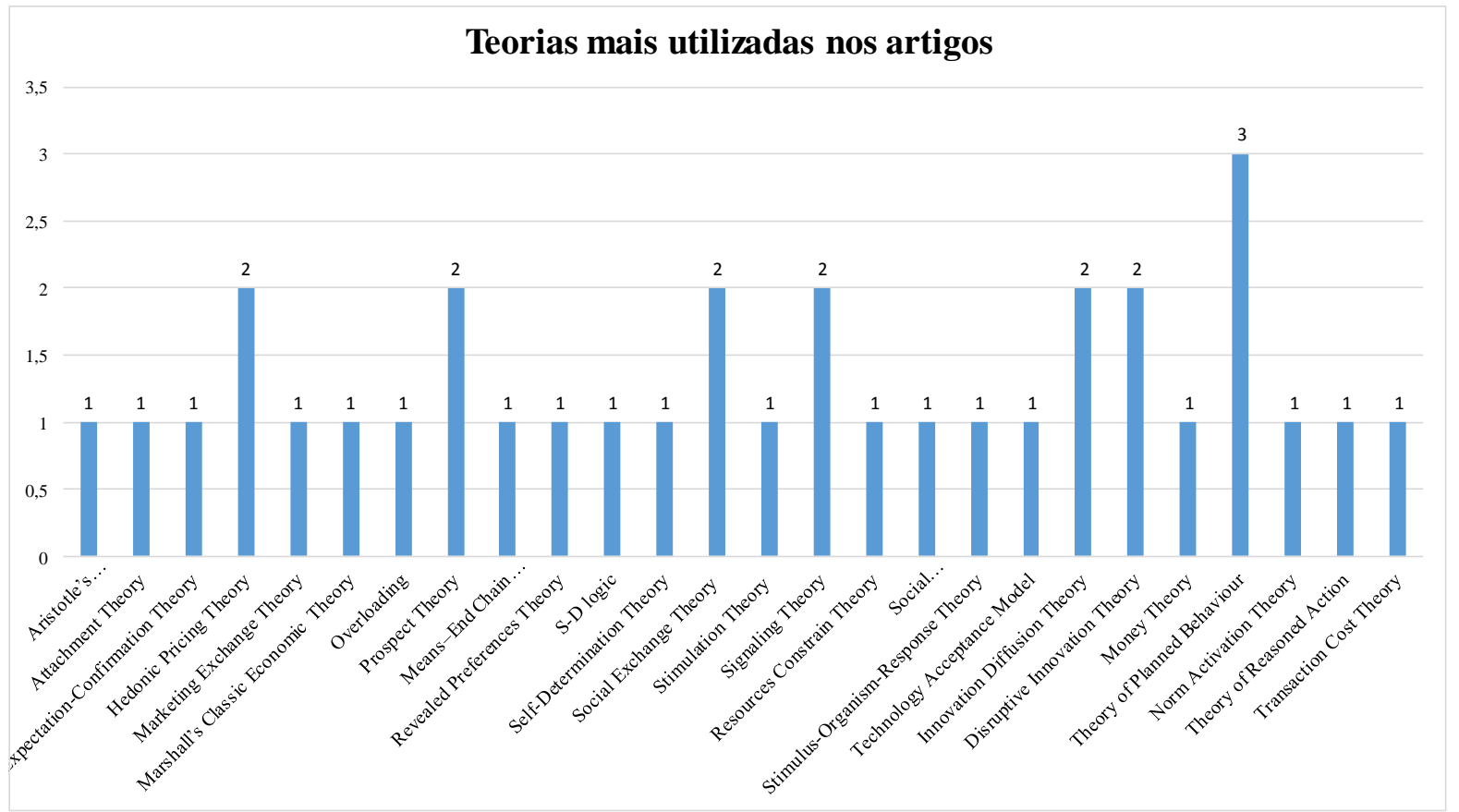

Fonte: Elaborado pelos autores.

Todas essas teorias têm como ponto comum a racionalização de comportamentos. Buscam esclarecer aspectos racionais que explicam a expansão de fenômenos e cenários. Nascidas nos campos da Administração, Psicologia ou Economia, auxiliam também no 
entendimento de padrões que permeiam tais esferas e permitem a avaliação de múltiplos cenários. Além disso, essa situação reforça o que foi discutido anteriormente, visto que tal cenário caracteriza um objeto novo, o qual - tanto por sua natureza quanto complexidade enseja uma abordagem multidisciplinar a partir de teorias de diferentes campos do saber.

Em relação as abordagens, a figura 4 demonstra que nos estudos internacionais existe uma prevalência de estudos quantitativos frente aos qualitativos e aos baseados em métodos mistos. A produção internacional apresenta um predomínio de artigos baseados em empiria (50), enquanto a produção nacional encontra-se dividida igualmente entre artigos empíricos e não empíricos. Essa diferença pode estar fundamentada nas diferenças de maturidade do campo nos países.

Figura 4 - Quantidade de artigos baseados em abordagens de pesquisa qualitativas versus abordagens de pesquisa quantitativas versus abordagens de método misto

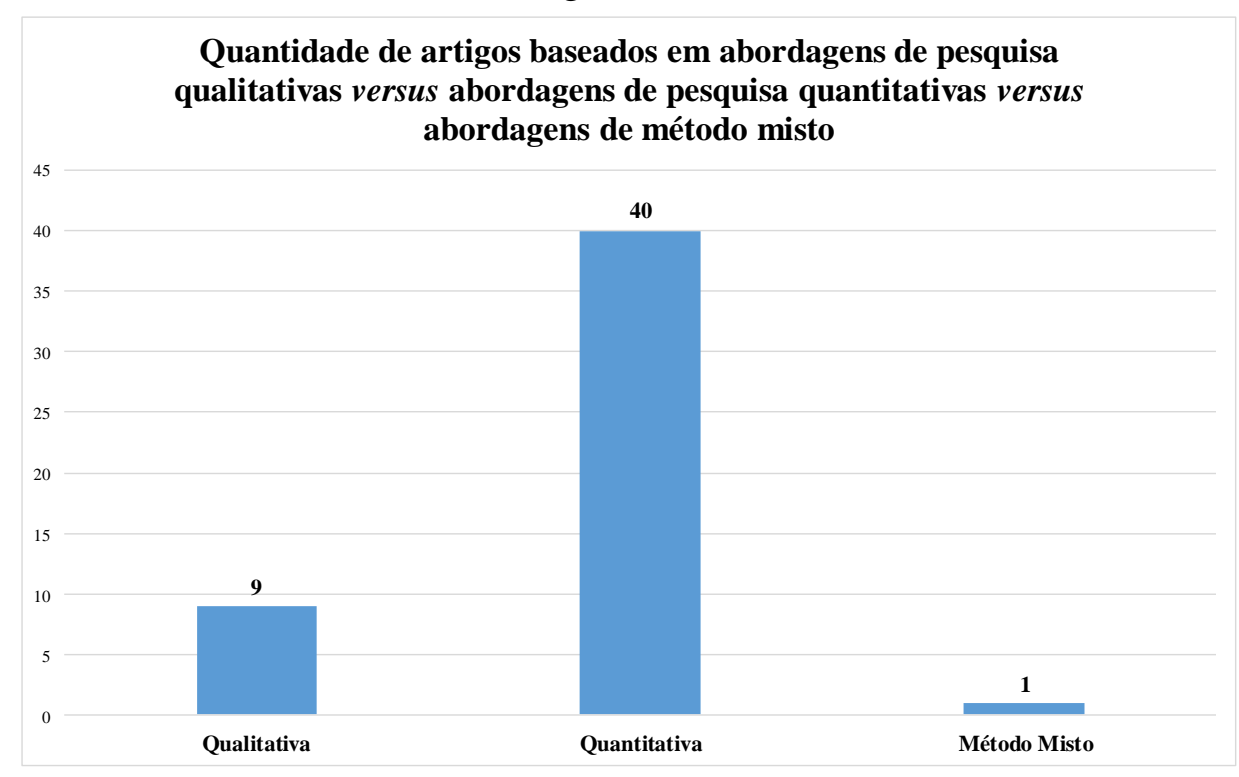

Fonte: Elaborado pelos autores.

Embora a pesquisa em Turismo e Hospitalidade esteja bem avançada e fundamentada em países como Estados Unidos e na Europa de maneira geral, programas de pós-graduação stricto sensu nacionais específicos nessas áreas - sabidamente conhecidos por serem os grandes responsáveis pela produção científica sobre este campo - são relativamente recentes, tendo iniciado suas atividades apenas na década de 1990 (Catramby, 2013), o que pode refletir no estágio metodológico em que as produções nacionais do campo se encontram.

Nas investigações nacionais, por sua vez, ocorre um predomínio de abordagens qualitativas. Essa conjuntura reforça os argumentos apresentados, sobretudo quando considerado que as pesquisas qualitativas são úteis para a obtenção de dados e conhecimentos que posteriormente fundamentarão a desenvolvimento de pesquisas quantitativas com foco no teste de hipóteses (Marujo, 2013). Além disso, encontra-se em consonância com a literatura nacional e internacional do campo do Turismo, para qual a pesquisa qualitativa valoriza a dimensão subjetiva dos atores envolvidos e, portanto, o macro entendimento dos fenômenos (Alves, 2011), enquanto a abordagem quantitativa permite a validação de questões específicas de pesquisa (Walle, 1997). 
No que tange as técnicas de pesquisa mais utilizadas internacionalmente (figura 5), observa-se o amplo domínio do emprego de análises matemáticas. As outras técnicas mais utilizadas são surveys, análise de conteúdo, estudo de caso e entrevistas em profundidade. Os artigos nacionais baseiam-se nas técnicas de entrevista em profundidade e análise de conteúdo.

Figura 5 - Técnicas de pesquisa mais utilizadas nos artigos

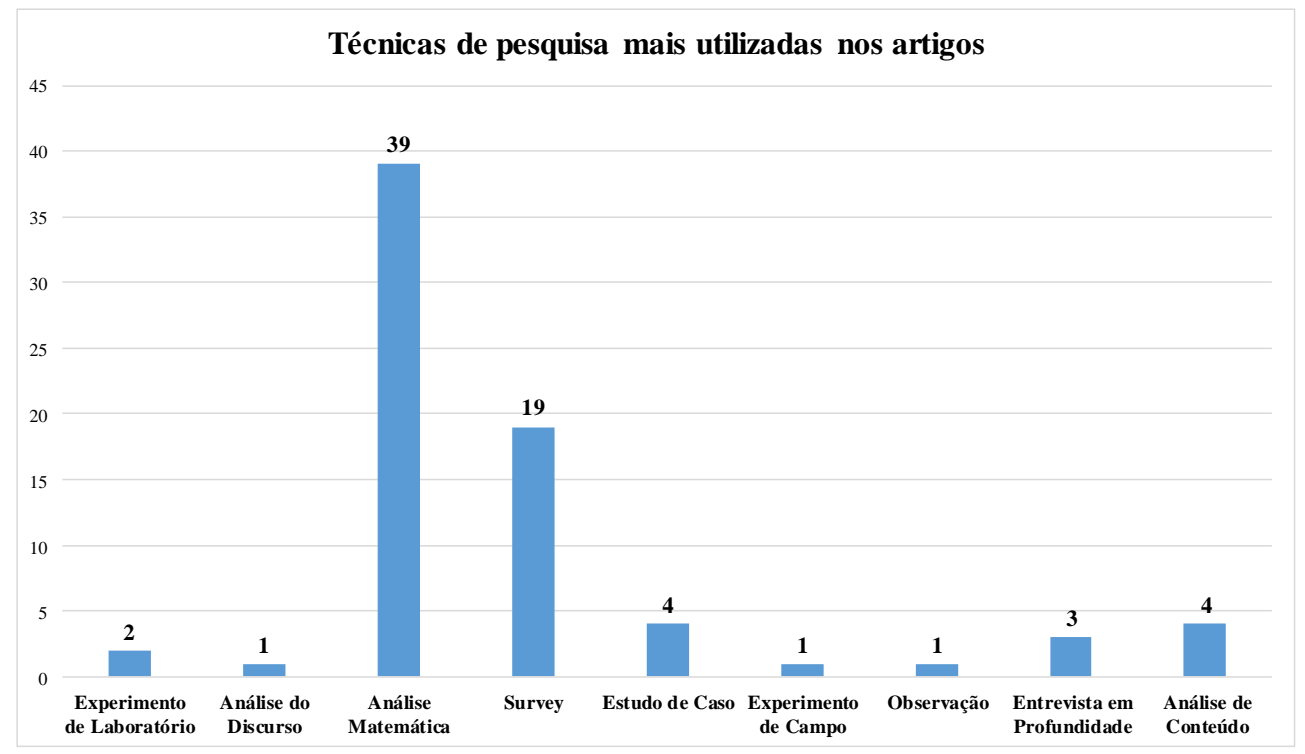

Fonte: Elaborado pelos autores.

Isso indica que, embora existam diversas possibilidades de estudo, parece existir uma convergência em torno do modo de se pesquisar. Se a natureza do problema de pesquisa indica qual técnica deverá ser utilizada (Creswell, 2007), os achados indicam interesses semelhantes de pesquisa.

Além disso, o amplo emprego de abordagens quantitativas reflete uma tendência por pesquisas empíricas mais focadas em detectar padrões que possam ser generalizados para o universo que suas amostras representam, o que sinaliza uma preocupação acerca da utilidade teórica e gerencial das descobertas.

Um detalhamento das análises matemáticas mais utilizadas nos artigos, apresentado na figura 6, ilustra o predomínio da utilização de regressões ${ }^{5}$, seguida pelas técnicas de modelagem de equações estruturais (SEM), teste t e ANOVA.

Esses dados indicam uma tendência de abordagens baseadas em testes de modelos centrados em explicar/prever variações em diversas variáveis dependentes diferentes, confirmando uma predisposição a avenidas semelhantes de pesquisa. Além disso, a utilização dessas técnicas permitem avanços de cunho teórico a partir de abordagens exploratórias, aspecto necessário dada a natureza recente do objeto.

\footnotetext{
${ }^{5}$ Já contabilizando as regressões utilizadas em análises econométricas.
} 
Figura 6 - Análises matemáticas mais frequentes nos artigos

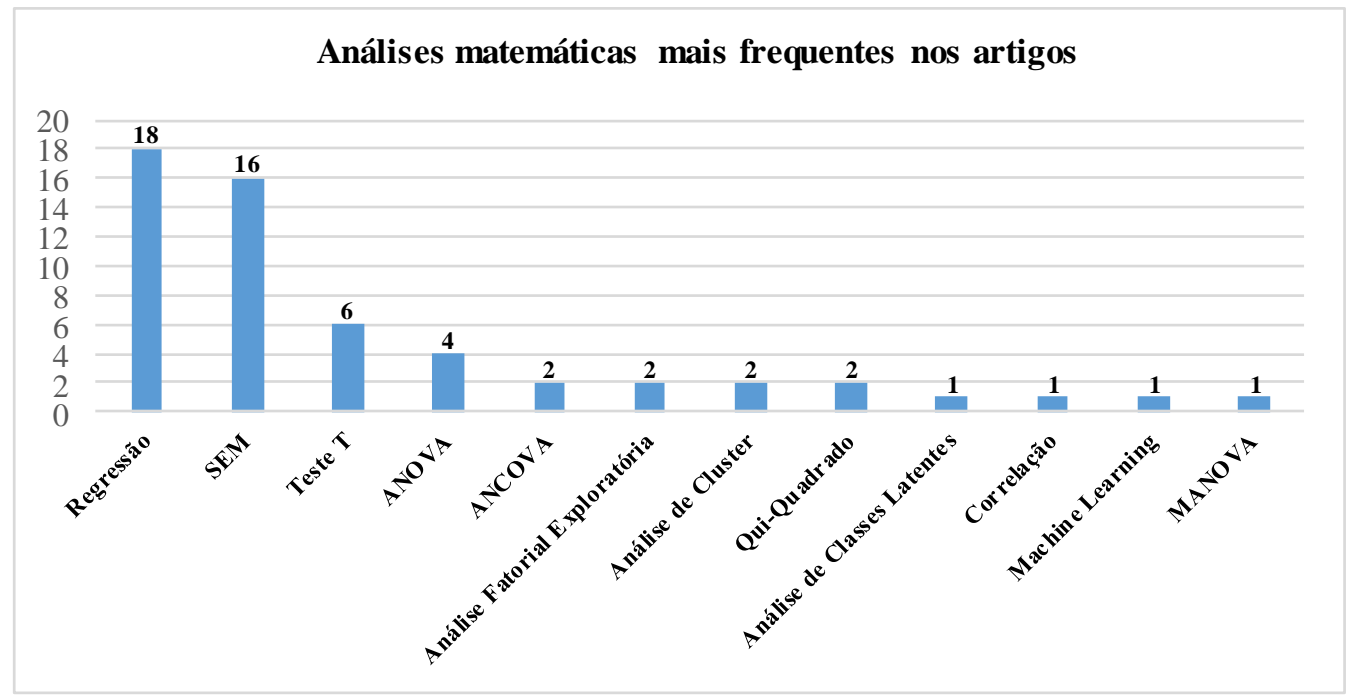

Fonte: Elaborado pelos autores.

Uma análise dos tipos de efeitos mais presentes nos artigos internacionais (figura 7) evidencia um equilíbrio entre os achados, com efeitos econômicos, comportamentais e cognitivos sendo mais comuns. Na produção nacional não houve predomínio de nenhum tipo de efeito específico, existindo efeito psicológico, econômico e social de sentido.

Esses achados, além de ilustrarem que existem correntes bem estabelecidas sobre o rumo dos estudos e reforçarem e justificarem a presença do amplo sortimento de teorias e frameworks apresentado na figura 3, também buscam posicionar os estudos em Turismo e Hospitalidade no centro de uma corrente empírico-teórica caracterizada pelo entendimento acerca dos processos de tomada de decisão e seus impactos. Essa proposição é reforçada quando se considera que o caráter disruptivo da Airbnb (Guttentag, 2015) tem gerado uma sorte de alterações em paradigmas estabelecidos, reconfigurando comportamentos e movimentando uma grande quantidade de reservas.

Figura 7 - Tipos de efeito mais presentes nos artigos

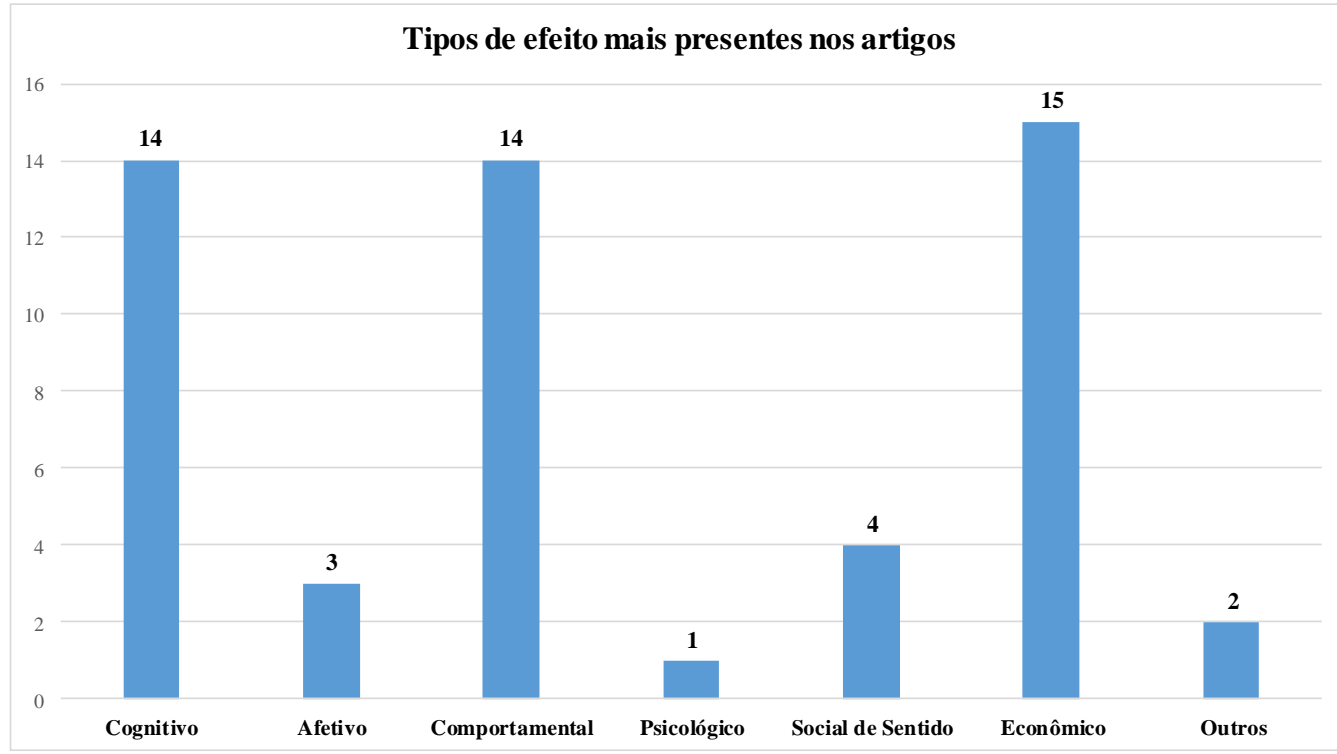

Fonte: Elaborado pelos autores.

PODIUM Sport, Leisure and Tourism Review | São Paulo | v. 9 | n. 1 | p. 117-140 | jan./abr. 2020 
Nesse sentido, percebe-se uma tendência de aproximação com o Marketing e suas abordagens teórico-metodológicas, incorporando-as nas investigações no contexto do Turismo e Hospitalidade em busca de aprofundar os conhecimentos sobre essas mudanças. Para isso, empregam diferentes recursos para melhor entender o objeto, resultando em diferentes tipos de efeitos observados.

Os dados secundários são as unidades de análise mais empregadas (figura 8) em artigos internacionais, seguida por dados primários obtidos de adultos. No cenário nacional, ocorre o inverso. Isso pode ser explicado pelo cenário no qual a Airbnb está inserida.

Figura 8 - Unidade de análise mais empregada nos artigos

Unidade de análise mais empregada

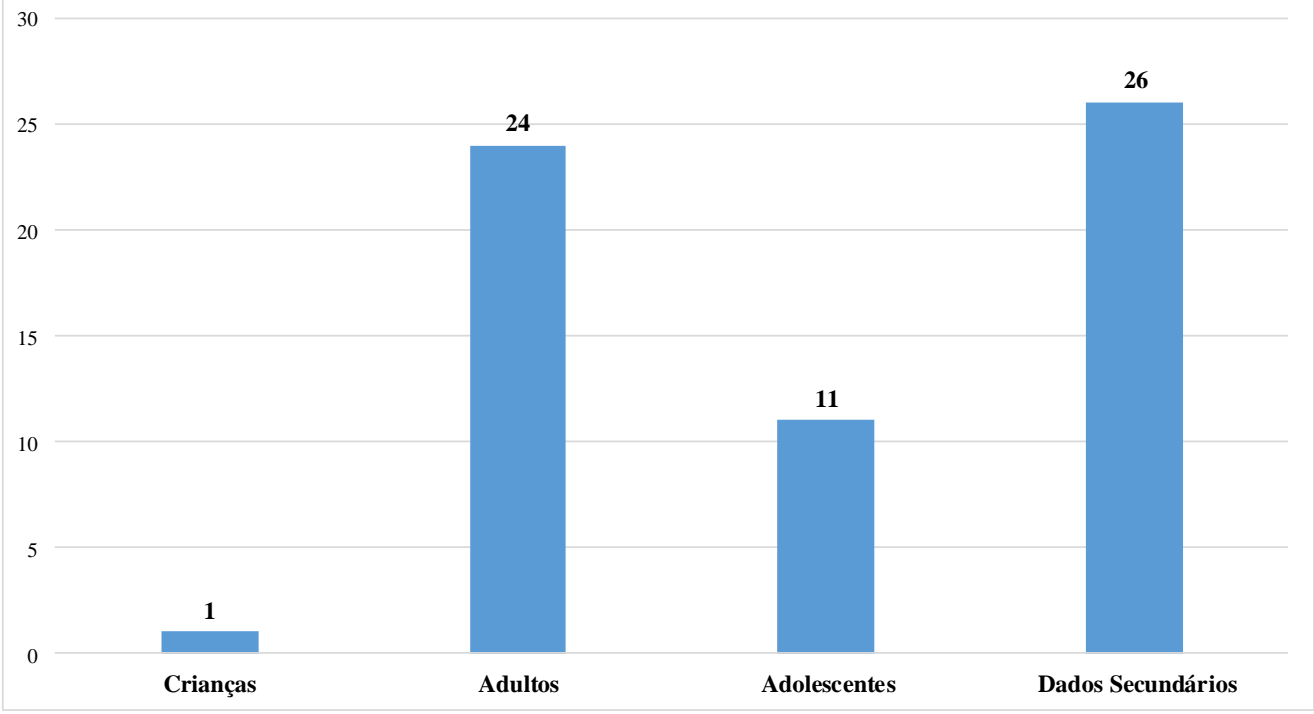

Fonte: Elaborado pelos autores.

Por ser uma empresa relativamente nova, ainda existe dificuldade em acessar sujeitos que utilizam o serviço dado o espaço em que ele se encontra ser um nicho segmentado (Guttentag et al., 2018). Nesse sentido, o surgimento de empresas como a AirDNA ${ }^{6}$ e a Inside $A i r b n b^{7}$, que fornecem dados sobre a Airbnb, torna mais atrativa a utilização de dados secundários. A preferência por adultos se dá na busca pela validade ecológica, buscando poder de generalização para os achados.

Também deve-se destacar que pesquisas qualitativas permitem a geração de insights a partir de amostras menores do que as necessárias para o emprego de análises quantitativas, o que auxilia o entendimento do cenário nacional.

Analisando a autoria dos artigos internacionais, os pesquisadores puderam constatar que o pesquisador com maior número de publicações é Daniel Guttentag, que assina - entre autor principal e coautor - um total de cinco publicações. O quadro $2^{8}$ apresenta os principais autores internacionais sobre a temática. Nas investigações nacionais analisadas, não houve o predomínio de um pesquisador específico, com todos tendo assinado apenas uma publicação.

\footnotetext{
${ }^{6}$ Disponível em https://www.airdna.co/.

${ }^{7}$ Disponível em http://insideairbnb.com/index.html.

${ }^{8}$ Dado seu objetivo, o quadro 2 apresenta apenas os autores com duas ou mais publicações.
} 
Quadro 2 - Principais autores dos artigos internacionais sobre Airbnb

\begin{tabular}{|l|c|c|}
\hline \multicolumn{2}{|c|}{ Principais autores dos artigos internacionais sobre Airbnb } \\
\hline \multicolumn{1}{|c|}{ Autor(a) } & Filiação & Quantidade de Artigos \\
\hline & & 5 \\
\hline Daniel Guttentag & College of Charleston - EUA & 4 \\
\hline Karen L. Xie & University of Denver - EUA & 3 \\
\hline Ulrich Gunter & MODUL University Vienna - Áustria & 3 \\
\hline Zhenxing (Eddie) Mao & Cal Poly Pomona University - EUA & 2 \\
\hline Dae-Young Kim & University of Missouri - EUA & 2 \\
\hline Barbara Neuhofer & Salzburg University of Applied Sciences & 2 \\
\hline Beatriz Benítez-Aurioles & - Austria & 2 \\
\hline Chris Gibbs & University of Malaga - Espanha & 2 \\
\hline Chulmo Koo & Ryerson University - Canadá & 2 \\
\hline Hanna Lee & Kyung Hee University - Coréia do Sul & 2 \\
\hline Hwansuk Chris Choi & University of Maryland - EUA & 2 \\
\hline Irem Önder & University of Guelph - Canadá & 2 \\
\hline Jym Morton & University of Massachusetts - EUA & \\
\hline Kyungmin Lee & Ryerson University - Canadá & 2 \\
\hline Lena Jingen Liang & Ohio State University - EUA & 2 \\
\hline Linchi Kwok & University of Guelph - Canadá & 2 \\
\hline Sara Dolnicar & Cal Poly Pomona University - EUA & 2 \\
\hline Seunghwan Lee & University of Queensland - Austrália & \\
\hline Stephen L.J. Smith & University of Missouri - EUA & \\
\hline Sung-Byung Yang & University of Waterloo - Canadá & 2 \\
\hline Ulrike Gretzel & Kyung Hee University - Coréia do Sul & \\
\hline
\end{tabular}

Fonte: Elaborado pelos autores.

A presença de um número significativo de autores com dois ou mais artigos e suas respectivas filiações mostram indícios de que a produção sobre o tema encontra-se distribuída entre vários centros de pesquisa, reafirma o interesse da comunidade científica mundial para com a Airbnb enquanto objeto e reafirma a complexidade que permeia suas múltiplas dimensões.

Esse argumento é corroborado quando analisa-se as produções destes autores. Os achados apontam indícios de que cada continente possui uma preferências por determinados tipos de estudos. Os pesquisadores europeus concentram suas investigações em temas como precificação, co-criação de valor e estudos sobre anfitriões. Na Ásia, os estudos se concentram em analisar fatores associados ao comportamento dos usuários, especialmente o desenvolvimento de confiança entre as partes envolvidas. Na Oceania, o foco se concentra em sustentabilidade e em estudos sobre anfitriões. Os estudos norte-americanos englobam as categorias apresentadas nos demais continentes.

Conforme apontado previamente, por ser um fenômeno recente, as pesquisas sobre Airbnb contam com um grande leque de possibilidades de questões a serem investigadas. Nesse sentido, o estudo de Guttentag (2015) mapeia uma série de problemas de pesquisa divididos em seis grandes áreas ${ }^{9}$ que podem ser utilizados para estudar aspectos associados à Airbnb.

Porém, uma análise longitudinal dos artigos que compõem a amostra aponta que as publicações tem se concentrado em investigar a alguns aspectos específicos associados a plataforma, a saber: (1) razões para adoção e reutilização do serviço, (2) seus impactos em

\footnotetext{
${ }^{9}$ As grandes áreas de pesquisa elencadas por Guttentag (2015) foram 'impactos nos destinos', 'impactos nas acomodações', 'tipo de apelo', 'lealdade', 'escolhendo entre as ofertas no Airbnb' e 'atitudes dos moradores locais' (tradução dos autores).
} 
hotéis e outros provedores de hospedagem, (3) aspectos que levam a opção por um determinado oferta/anúncio, (4) precificação, (5) transformações causadas pelo aumento da oferta de acomodações baseadas em aluguel de curto prazo e (6) co-criação de valor.

Paralelamente, as respectivas sugestões para estudos futuros concentram-se em replicações com amostras diferentes ou maiores, visando a validade ecológica dos achados, replicações em contextos diferentes e estabelecer controles para variáveis externas, além de sugerirem pesquisas que aprofundem os achados pelo acréscimo de variáveis às análises feitas.

Diante deste cenário, pode-se perceber que, embora diversos temas tenham sido examinados, muitas das avenidas de pesquisa oferecidas por Guttentag (2015) continuam pouco ou inexploradas, constituindo proveitosas lacunas a serem endereçadas em futuras investigações sobre a Airbnb.

\subsection{Análise Bibliométrica}

Visando observar o relacionamento existentes entre os papers da amostra e a identificação dos pilares que fundamentam as pesquisas sobre Airbnb, conduziu-se uma análise bibliométrica de co-citação por meio de uma análise fatorial exploratória (AFE).

Os resultados apresentados na tabela 1 foram obtidos na vigésima extração. Para a realização da análise, empregou-se uma rotação ortogonal por meio do método 'varimax', resultando em um KMO de 0,812 e a comunalidade mais baixa sendo de 0,616. Foram encontrados três fatores que juntos explicam $72,24 \%$ da variância total.

O primeiro fator, nomeado 'pricing e impacto econômico' (alfa de Cronbach $=0,912$ ), é composto por seis artigos que trabalham especificamente temáticas financeiras. Abordando questões como a precificação de quartos de hotéis (Zhang, Ye, \& Law, 2011), de 'BnBs' (Monty e Skidmore, 2003), de serviços de hospedagem vinculados à economia do compartilhamento (Wang \& Nicolau, 2017) ou ainda discutindo o algoritmo de precificação da Airbnb (Hill, 2015), contribuem para reforçar a discussão acerca do impacto financeiro promovido pela Airbnb na indústria hoteleira (Zervas, Proserpio, \& Byers, 2017). Aqui, o estudo de Rosen (1974) cria um ponto comum ao contribuir para a discussão sobre aspectos hedônicos e seus impactos na disposição do quanto pagar.

Esse fator parece salientar a importância de fundamentar a relevância de estudar a Airbnb no aspecto financeiro, um dos principais pilares responsáveis pela ascensão da Airbnb. Desta forma, estes artigos criam um conjunto de evidências que sinalizam uma mudança sobre os desejos dos usuários de acomodações de curto prazo, contribuindo para a reconfiguração de políticas de precificação atrelada ao consumo colaborativo e, consequentemente, criando um espaço para pesquisas sobre a Airbnb a partir de aspectos de interesses teóricos e mercadológicos. 
Tabela 1 - Fatores obtidos por meio da Análise Fatorial Exploratória.

\begin{tabular}{|c|c|c|c|c|c|}
\hline \multicolumn{2}{|c|}{ Pricing e Impacto Econômico } & \multicolumn{2}{|c|}{ Sustentáculo Teórico } & \multicolumn{2}{|c|}{$\begin{array}{c}\text { Estado da Arte e Estudos } \\
\text { Futuros }\end{array}$} \\
\hline Zhang, Ye e Law, 2011 & 0,900 & Gefen, 2000 & 0,885 & $\begin{array}{l}\text { Karlsson e } \\
\text { Dolnicar, } 2016\end{array}$ & 0,849 \\
\hline $\begin{array}{l}\text { Monty e Skidmore, } \\
2003\end{array}$ & 0,852 & Belk, 2010 & 0,825 & Cheng, 2016b & 0,834 \\
\hline Rosen, 1974 & 0,842 & Hirschman, 1980 & 0,787 & Heo, 2016 & 0,810 \\
\hline Hill, 2015 & 0,826 & $\begin{array}{l}\text { Hamari, Sjöklint e } \\
\text { Ukkonen, } 2016\end{array}$ & 0,767 & Cheng, 2016a & 0,758 \\
\hline $\begin{array}{l}\text { Zervas, Proserpio e } \\
\text { Byers, } 2017\end{array}$ & 0,8 & Ajzen, 1991 & 0,744 & $\begin{array}{l}\text { Tussyadiah e } \\
\text { Zach, } 2017\end{array}$ & 0,707 \\
\hline Wang e Nicolau, 2017 & 0,783 & $\begin{array}{l}\text { Stors e } \\
\text { Kagermeier, } 2015\end{array}$ & 0,688 & & \\
\hline $\begin{array}{l}\text { Variância Explicada } \\
(\%)\end{array}$ & $26,44 \%$ & $\begin{array}{l}\text { Variância } \\
\text { Explicada (\%) }\end{array}$ & $23,05 \%$ & $\begin{array}{l}\text { Variância } \\
\text { Explicada (\%) }\end{array}$ & $20,75 \%$ \\
\hline
\end{tabular}

Fonte: Adaptado pelos autores de Guerrazzi, Brandão, de Campos Junior e Lourenço (2015).

O segundo fator, intitulado 'sustentáculo teórico' (alfa de Cronbach $=0,878$ ), é formado por seis papers que constituem bases teóricas que fundamentam estudos sobre Airbnb.

Apresentando variáveis / fenômenos / teorias como familiaridade e confiança em ambientes de comércio eletrônico (Gefen, 2000), o conceito de compartilhamento (Belk, 2010), construtos que influenciam o comportamento do consumidor como inovação, busca por novidades e criatividade do consumidor (Hirschman, 1980), razões para engajamento no consumo colaborativo (Hamari, Sjöklint, \& Ukkonen, 2016), a teoria do comportamento planejado (Ajzen, 1991) e motivos para a adesão ao serviço oferecido pela Airbnb (Stors \& Kagermeier, 2015), esse fator reúne artigos que possuem um grande número de citações, caracterizando papers seminais sobre suas respectivas temáticas. Assim, ilustra um framework que auxilia a fundamentação teórica dos estudos sobre o fenômeno Airbnb. Em um fenômeno recente - a Airbnb tem apenas onze anos de existência - como este, faz-se mister entender as dinâmicas que permeiam sua utilização e como tais mecânicas se manifestam nesse cenário.

Por sua vez, o terceiro fator, chamado 'estado da arte e estudos futuros' (alfa de Cronbach $=0,850$ ), é constituído por cinco artigos que mapeiam temáticas relevantes para estudos sobre economia colaborativa e Airbnb.

Passando por razões pela qual sujeitos decidem ofertar acomodação em redes ponto-aponto (Karlsson \& Dolnicar, 2016), revisões da literatura sobre a economia do compartilhamento e sugestões de estudos futuros na área de cunho geral (Cheng, 2016b) ou focando especificamente no campo do Turismo (Heo, 2016; Cheng, 2016a) e atributos que influenciam a adesão junto à serviços de acomodação via redes ponto-a-ponto (Tussyadiah \& Zach, 2017), estes artigos possuem como característica comum contribuírem para o posicionamento de gaps de pesquisa, fornecendo justificativas teóricas que possibilitem a realização de estudos sobre a temática a partir do ineditismo de uma investigação sobre um tema considerado cientificamente relevante de ser discutido. 


\section{Conclusão}

Este artigo teve como objetivo apresentar as características dos artigos que analisam a Airbnb publicados nos principais periódicos científicos internacionais e nos periódicos científicos nacionais pertencentes ao campo do Turismo e ao campo da Administração entre 2008 e 2018. Para isso, analisou-se inicialmente os 40 principais periódicos científicos internacionais pertencentes aos campos do Turismo e da Administração escolhidos a partir do indicador $H$-Index e todos os periódicos científicos nacionais dessas áreas indexados no repositório de periódicos Spell para localizar artigos que contivessem o termo 'Airbnb' no título, resumo ou nas palavras-chave e que foram publicados no período de 2008 a 2018.

Após realização de uma filtragem, os autores encontraram um total de 57 artigos distribuídos entre 14 periódicos, os quais compuseram a amostra final que foi analisada nesse estudo. A análise se deu a partir de um estudo bibliométrico, empregando inicialmente uma revisão sistemática, seguida de uma análise bibliométrica realizada por meio de um estudo de co-citações a partir de uma análise fatorial exploratória.

Os achados mostram que os artigos que analisam a Airbnb concentram-se em alguns periódicos, apresentando um crescimento exponencial ao longo dos anos, sendo majoritariamente não baseados em teoria, utilizando abordagem quantitativa, empregando como principais técnicas estatísticas regressões e SEM, focando em efeitos econômicos e empregando como principal unidade de análise dados secundários. $\mathrm{O}$ autor com mais publicações é Daniel Guttentag. As citações feitas pelos artigos da amostra fundamentam-se em três fatores, nomeados (1) 'Pricing e Impacto Econômico', (2) ‘Sustentáculo Teórico’ e (3) 'Estado da Arte e Estudos Futuros'.

Por ser uma pesquisa de cunho longitudinal, cobrindo as pesquisas sobre o objeto desde seu surgimento ao longo de um período de dez anos, os resultados apontam algumas questões relevantes. Durante o desenvolvimento das pesquisas sobre um objeto tão recente e, portanto, 'desconhecido', esperam-se muitos trabalhos de cunho exploratório, empíricos, mas não fundamentados em teoria, pois antes desse estágio de maturidade torna-se necessário entender mais sobre o objeto e suas mecânicas.

Nesse sentido, abordagens multidisciplinares são benéficas (Vera \& De Sevilha Gosling, 2017) e bem vindas. Espera-se pelo foco e escopo dos periódicos analisados, inclusive, valorosa contribuição de outros campos das Ciências Sociais Aplicadas como a Comunicação, que configura-se como uma dimensão chave na experiência de consumo do serviço ofertado pela Airbnb (Sthapit \& Jiménez-Barreto, 2019, o Direito e Arquitetura e Urbanismo, por exemplo, para um maior entendimento do objeto e seu impacto no campo do Turismo.

Paralelamente, também observou-se durante a produção da matriz de co-citação que os artigos que formaram a amostra apresentam poucas citações. Ao mesmo tempo que isso reflete a recência da temática, também mostra uma busca por explicações a partir de teorias oriundas de outros campos do conhecimento. Isso reforça a necessidade do desenvolvimento de teorias no domínio teórico do Turismo, as quais podem contribuir tanto para seu avanço enquanto campo científico quanto para maior entendimento de seus fenômenos.

Embora existam revisões sistemáticas sobre a economia compartilhada (Silveira, Petrini, \& Santos, 2016; Trenz, Frey, \& Veit, 2018), sobre o compartilhamento de hospedagem ponto-a-ponto (Prayag \& Ozanne, 2018) e sobre Airbnb (Humes \& Freire, 2018; Dann, Teubner, \& Weinhardt, 2019), a contribuição teórica deste artigo reside em avançar os achados feitos por Humes e Freire (2018) e Dann et al. (2019) por meio da realização de um estudo bibliométrico sobre a temática, algo inédito até o momento. Assim, esta pesquisa ao mesmo tempo abre caminho para aqueles que queiram compreender mais sobre o objeto - dado fato de

PODIUM Sport, Leisure and Tourism Review | São Paulo | v. 9 | n. 1 | p. 117-140 | jan./abr. 2020 
que oferecem-se informações sobre como ele tem sido estudado - e fornece um mapa de possíveis periódicos que publicam artigos que analisem a Airbnb.

A principal contribuição teórica deste estudo, entretanto, reside em seu potencial para endereçar avenidas futuras de pesquisa, atualizando as sugestões propostas por Guttentag (2015) e propondo novas searas de investigação. Neste sentido, como discutido anteriormente, muitas das propostas feitas por Guttentag (2015) continuam sendo oportunidades profícuas para estudos. Porém, a dinâmica do objeto e a constante mutação do ambiente da Hospitalidade revelam novos horizontes de pesquisa e dinâmicas emergentes do cenário atual.

Baseado nesse panorama, propõe-se uma agenda para estudos futuros baseada - mas não limitada - nas seguintes questões de pesquisa: (1) Como a mídia e seus atores contribuem para a adesão a Airbnb? (2) Como a Airbnb afeta as dinâmicas interacionais locais? (3) Os valores promovidos pela marca Airbnb dialogam com todos os seus usuários da mesma forma? (4) Como a identidade dos sujeitos se relaciona com a Airbnb? (5) Qual o papel dos anfitriões na intenção de reutilização do serviço? (6) Como o papel mediador desempenhado pela plataforma é percebido por hóspedes e anfitriões? (7) Qual é a percepção dos hóspedes sobre as recomendações feitas pela plataforma? (8) Qual é o impacto financeiro da Airbnb nas receitas de hotéis no Brasil? (9) Como esse impacto se dá nas receitas de hostels e pousadas? (10) No Brasil, a Airbnb é uma concorrente direta ou indireta dos hotéis?

O estudo, porém, não está imune a potenciais limitações. A primeira delas está baseada no corpus adotado para esse estudo. Dado que esta pesquisa concentrou-se em analisar apenas os 40 principais periódicos científicos internacionais pertencentes aos campos do Turismo e da Administração escolhidos a partir do indicador H-Index e todos os periódicos científicos nacionais dessas áreas indexados no repositório de periódicos Spell, estudos futuros devem estender o corpus de análise englobando mais periódicos internacionais e nacionais em sua amostra de pesquisa.

Uma segunda limitação está associada aos campos analisados. Partindo do fato de que este estudo analisou apenas periódicos pertencentes aos campos da Administração e do Turismo, estudos futuros devem ampliar o horizonte de pesquisa para novos campos do conhecimento visando aumentar a compreensão dos estudos que já foram realizados sobre esse objeto. Outro ponto é que este estudo incluiu na matriz de co-citações apenas artigos que possuíam três ou mais citações. Dessa forma, estudos futuros devem analisar conjuntos maiores de dados (ou seja, papers com um número menor de citações) para confirmar os achados apresentados neste estudo bibliométrico e / ou aprofundá-los.

O panorama encontrado mostra um cenário benéfico para estudos sobre a Airbnb, possibilitando o avanço do conhecimento científico sobre as mecânicas e dimensões do objeto e contribuindo para o entendimento de fenômeno e seus impactos no Turismo, na Administração e nos demais campos das Ciências Sociais Aplicadas. Desta forma, espera-se que o presente trabalho incentive pesquisas futuras sobre a Airbnb.

\section{Referências}

Ajzen, I. (1991). The theory of planned behavior. Organizational Behavior and Human Decision Processes, 50(2), 179-211.

Airbnb. (2019). Sobre nós. Recuperado de https://bit.ly/2SC3Krz.

Alves, M. L. B. (2011). Reflexões sobre a pesquisa qualitativa aplicada ao turismo. Revista Turismo em Análise, 22(3), 599-613. 
Alves, D. F., Brandão, H. A., \& Valdevino, A. M. (2018). Consumo colaborativo como alternativa: percepção dos anfitriões da plataforma Airbnb na região metropolitana do Cariri cearense. Marketing \& Tourism Review, 3(2).

Ap. (2016, 23 de setembro). Marriott compra Starwood e se torna maior rede de hotéis de mundo. $O$ Globo. Recuperado de https://glo.bo/32Oe9Vj.

Belk, R. (2010). Sharing. Journal of Consumer Research, 36(5), 715-734.

Belk, R. W. (2013). Extended self in a digital world. Journal of Consumer Research, 40(3), 477-500.

Bezerra, L. T., \& Ferreira, L. V. (2018). Turismo, viagem e economia compartilhada: as experiências relatadas pelos usuários do Couchsurfing em Natal/RN. Turismo, Visão e Ação, 20(3), 375-388.

Bornelli, J. (2016, 06 de dezembro). Airbnb: a maior rede de hotéis do mundo que não possui nenhum quarto de hotel. StartSe. Recuperado de https://bit.ly/2CwC3ef.

Botsman, R., \& Rogers, R. (2011). O que é meu é seu: como o consumo colaborativo vai mudar o nosso mundo. Porto Alegre: Bookman Editora.

Bridges, J., \& Vásquez, C. (2018). If nearly all Airbnb reviews are positive, does that make them meaningless?. Current Issues in Tourism, 21(18), 2057-2075.

Camilleri, J., \& Neuhofer, B. (2017). Value co-creation and co-destruction in the Airbnb sharing economy. International Journal of Contemporary Hospitality Management, 29(9), 2322-2340.

Catramby, T. (2013). Em que cenário foi criado o curso superior de Turismo no Brasil?. Artigo apresentado no XXVII Simpósio Nacional de História: Conhecimento histórico e diálogo social (pp.1-15). Natal, RN. Recuperado de https://bit.ly/2mcYtvv.

Cheng, M. (2016a). Current sharing economy media discourse in tourism. Annals of Tourism Research, 60, 111-114.

Cheng, M. (2016b). Sharing economy: A review and agenda for future research. International Journal of Hospitality Management, 57, 60-70.

Creswell, J. W. (2007). Projeto de Pesquisa: métodos qualitativo, quantitativo e misto. Porto Alegre: Artmed.

Dann, D., Teubner, T., \& Weinhardt, C. (2019). Poster child and guinea pig-insights from a structured literature review on Airbnb. International Journal of Contemporary Hospitality Management, 31(1), 427-473.

Davidson, L. (2016, 18 de fevereiro). Here's how much money people are making from the sharing economy. The Telegraph. Recuperado de https://bit.ly/35c4qtQ. 
Edelman, B. G., \& Luca, M. (2014). Digital discrimination: The case of Airbnb.com (Harvard Business School NOM Unit Working Paper No. 14-054). Recuperado de https://hbs.me/2IdIrdI.

Field, A. (2009). Descobrindo a estatística usando o SPSS. Porto Alegre: Bookman Editora.

Gefen, D. (2000). E-commerce: the role of familiarity and trust. Omega, 28(6), 725-737.

Guerrazzi, L. A. d. C., Brandão, M. M., de Campos Junior, H., \& Lourenço, C. E. (2015). Pesquisa em Marketing e Estratégia nos principais periódicos internacionais: Um estudo bibliométrico sobre publicações no século XXI. Revista Ibero Americana de Estratégia, 14(1), 7-27.

Guttentag, D. (2015). Airbnb: disruptive innovation and the rise of an informal tourism accommodation sector. Current Issues in Tourism, 18(12), 1192-1217.

Guttentag, D., Smith, S., Potwarka, L., \& Havitz, M. (2018). Why tourists choose Airbnb: A motivation-based segmentation study. Journal of Travel Research, 57(3), 342-359.

Hamari, J., Sjöklint, M., \& Ukkonen, A. (2016). The sharing economy: Why people participate in collaborative consumption. Journal of the Association for Information Science and Technology, 67(9), 2047-2059.

Hair, J. F., Black, W. C., Babin, B. J., Anderson, R. E., \& Tatham, R. L. (2009). Análise multivariada de dados. Porto Alegre: Bookman.

Heo, Y. (2016). Sharing economy and prospects in tourism research. Annals of Tourism Research, 58, 166-170.

Hill, D. (2015). How much is your spare room worth?. IEEE Spectrum, 52(9), 32-58.

Hirschman, E. C. (1980). Innovativeness, novelty seeking, and consumer creativity. Journal of Consumer Research, 7(3), 283-295.

Humes, L. B., \& Freire, O. B. d. L. (2018). Consumo mediado por tecnologia como forma de midiatização do consumo - $\mathrm{O}$ que temos pesquisado sobre a Airbnb?. Artigo apresentado no $41^{\circ}$ Congresso Brasileiro de Ciências da Comunicação (pp.1-13). Joinville, SC. Recuperado de https://bit.ly/2lpHohy.

Karlsson, L., \& Dolnicar, S. (2016). Someone's been sleeping in my bed. Annals of Tourism Research, 58, 159-162.

Kim, K., Hayes, J. L., Avant, J. A., \& Reid, L. N. (2014). Trends in advertising research: A longitudinal analysis of leading advertising, marketing, and communication journals, 1980 to 2010. Journal of Advertising, 43(3), 296-316.

Lock, S. (2019, 09 de agosto). Number of sharing economy users in the United States from 2016 to 2021 (in millions). Statista. Recuperado de https://bit.ly/359C2bs. 
Manoharan, A., \& Singal, M. (2017). A systematic literature review of research on diversity and diversity management in the hospitality literature. International Journal of Hospitality Management, 66, 77-91.

Marriott. (2015). Marriott International adquire a Starwood Hotels \& Resorts em todo o mundo, criando a maior empresa hoteleira do mundo. Recuperado de https://bit.ly/35comMP.

Marujo, N. (2013). A pesquisa em turismo: reflexões sobre as abordagens qualitativa e quantitativa. Revista de Investigación em Turismo y Desarrollo Local, 6(14), 01-16.

Matos, B. G., \& Marques, L. C. (2018). Relacionalidade em rede: Cama e Café. Marketing \& Tourism Review, 3(3).

McCracken, G. (2015). Cultura \& Consumo II: mercados, significados e gerenciamento de marcas. Rio de Janeiro: Mauad.

Molz, J. G. (2014). Toward a network hospitality. First Monday, 19(3).

Monty, B., \& Skidmore, M. (2003). Hedonic pricing and willingness to pay for bed and breakfast amenities in Southeast Wisconsin. Journal of Travel Research, 42(2), 195-199.

Moreira, M. A. N., \& Gomes, C. L. (2018). A hospitalidade na rede social Couchsurfing: Cruzando a soleira virtual em Jaguarão, no extremo Sul do Brasil. Revista Brasileira de Pesquisa em Turismo, 12(2), 1-24.

Piovesan, A., \& Temporini, E. R. (1995). Pesquisa exploratória: procedimento metodológico para o estudo de fatores humanos no campo da saúde pública. Revista de Saúde Pública, 29, 318-325.

Prayag, G., \& Ozanne, L. K. (2018). A systematic review of peer-to-peer (P2P) accommodation sharing research from 2010 to 2016: progress and prospects from the multi-level perspective. Journal of Hospitality Marketing \& Management, 27(6), 649-678.

PWC. (2015). The Sharing Economy: Consumer Intelligence Series. (Relatório de Pesquisa). Londres, GBR: PricewaterhouseCoopers.

Quevedo-Silva, F., Santos, E. B. A., Brandão, M. M., \& Vils, L. (2016). Bibliometric study: guidelines on its application. Brazilian Journal of Marketing, 15(2), 246-262.

Rosen, S. (1974). Hedonic prices and implicit markets: product differentiation in pure competition. Journal of Political Economy, 82(1), 34-55.

Sampaio, R. F.; Mancini, M. C. (2007). Estudos de revisão sistemática: um guia para síntese criteriosa da evidência científica. Revista Brasileira de Fisioterapia, 11(1), 83-89. 
Santos, E. B. A., \& Freire, O. B. D. L. (2013). The influence of music on consumer purchase behavior in retail environment. Independent Journal of Management \& Production, 4(2), 537-548.

Silveira, L. M. d., Petrini, M., \& Santos, A. C. M. Z. d. (2016). Economia compartilhada e consumo colaborativo: o que estamos pesquisando?. REGE - Revista de Gestão, 23(4), 298305.

SPC. (2019, 13 de agosto). Oito em cada dez brasileiros estão dispostos a adotar mais práticas de consumo colaborativo, revela estudo CNDL/SPC Brasil. Recuperado de https://bit.ly/2XkZkIH.

Sthapit, E., \& Jiménez-Barreto, J. (2019). You never know what you will get in an Airbnb: Poor communication destroys value for guests. Current Issues in Tourism, 22(19), 23152318.

Stors, N., \& Kagermeier, A. (2015). Motives for using Airbnb in metropolitan tourism - Why do people sleep in the bed of a stranger?. Regions Magazine, 299(1), 17-19.

Touryalai, H. (2019, 20 de maio). Global 2000: os maiores grupos hoteleiros em 2019. Forbes. Recuperado de https://bit.ly/2OeXyF0.

Trenz, M., Frey, A., \& Veit, D. (2018). Disentangling the facets of sharing: a categorization of what we know and don't know about the sharing economy. Internet Research, 28(4), 888-925.

Tussyadiah, I. P., \& Zach, F. (2017). Identifying salient attributes of peer-to-peer accommodation experience. Journal of Travel \& Tourism Marketing, 34(5), 636-652.

Vera, R., Alves, L., \& de Sevilha Gosling, M. (2017). Economia compartilhada no turismo: Uma discussão teórica sobre o consumo colaborativo e o compartilhamento. Revista Eletrônica de Estratégia \& Negócios, 10(1), 226-251.

Walle, A. H. (1997). Quantitative versus qualitative tourism research. Annals of Tourism Research, 24(3), 524-536.

Wang, D., \& Nicolau, J. L. (2017). Price determinants of sharing economy based accommodation rental: A study of listings from 33 cities on Airbnb.com. International Journal of Hospitality Management, 62, 120-131.

Warwick. (2018, 02 de julho). UK sharing economy usage rises by 60 per cent. The University of Warwick. Recuperado de https://bit.ly/2Qpje3Z.

Webster, J., \& Watson, R. T. (2002). Analyzing the past to prepare for the future: Writing a literature review. MIS Quarterly, xiii-xxiii. 
William, E., \& Martell, E. P. (2008). Turismo 2.0. La web social como plataforma para desarrollar un ecosistema turístico basado en el conocimiento. Estudios Turísticos, 178, 113-147.

Yannopoulou, N., Moufahim, M., \& Bian, X. (2013). User-generated brands and social media: Couchsurfing and AirBnb. Contemporary Management Research, 9(1).

Zervas, G., Proserpio, D., \& Byers, J. W. (2017). The rise of the sharing economy: Estimating the impact of Airbnb on the hotel industry. Journal of Marketing Research, 54(5), 687-705.

Zhang, Z., Ye, Q., \& Law, R. (2011). Determinants of hotel room price: An exploration of travelers' hierarchy of accommodation needs. International Journal of Contemporary Hospitality Management, 23(7), 972-981.

Zimmermann, D. D., Humes, L. B., \& Meira, K. d. M. A. (2019). Navegar é preciso: Narrativas midiatizadas do viajante contemporâneo sobre a Airbnb no YouTube. Artigo apresentado no X Pró-Pesq PP - Encontro Nacional de Pesquisadores em Publicidade e Propaganda (pp.1-15). São Paulo, SP. 